\title{
Demo Projects Introduce New Class of Natural Gas Vehicles
}

Highlights in

Research \& Development

NREL teams with industry and government stakeholders to identify and address technical and marketplace barriers.

With the United States' wealth of natural gas reserves, vehicles powered using this plentiful domestic resource are important components of a transportation portfolio designed to improve energy efficiency, national security, and air quality. At the same time, numerous technical and marketplace barriers must be overcome before wider adoption of natural gas vehicles can be realized.

Currently, most natural gas vehicles are passenger vehicles and light-duty trucks, and many have been converted from conventional gasoline engines, rather than factory produced. There is a significant potential for economic and environmental benefits for heavy-duty vehicles, and the National Renewable Energy Laboratory (NREL) is working with stakeholders to increase product

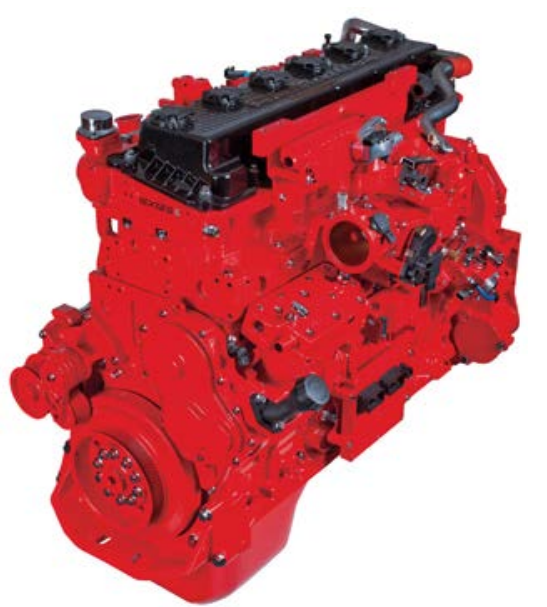

A Cummins Westport ISX12 G engine. Image from Cummins Westport, Inc. availability for natural gas-powered medium- and heavy-duty commercial vehicles. As a result, NREL — supported by the U.S. Department of Energy, the California Energy Commission, the South Coast Air Quality Management District, and industry partners-launched a program to develop high-efficiency, low-emission natural gas engines for commercialization, integrate the engines into a range of medium- and heavy-duty commercial vehicles, and assess performance of these vehicles with on-road demonstrations.

NREL research is addressing this critical gap in the 11- to 13-liter engine category needed to power vocational vehicles ranging from garbage trucks and transit buses to Class 8 long-haul freight trucks. Two projects are focused on certification and commercial production of natural gas engines, utilizing both compressed natural gas and liquefied natural gas. Cummins Westport, a leader in natural gas engine technology for the automotive market, developed the 11.9-liter ISX12 G engine for commercial production. Sponsored by NREL, Cummins Westport's on-road development and demonstration program has put the new engine through its paces in models from six truck manufacturers, accumulating more than 1 million miles in various duty cycles. Engineering specialists at Southwest Research Institute, in cooperation with global engine manufacturers at Doosan Infracore, are developing an 11.1-liter natural gas engine.

For more than a decade, NREL has been involved in developing natural gas engines and related technology, as well as supporting fleet operator decision making and deployment efforts. Although natural gas is not yet in widespread use in most medium- and heavy-duty commercial vehicle applications, NREL research is helping to accelerate natural gas vehicle adoption by enabling development and demonstration of new engines that will deliver the strong performance and energy efficiency benefits required to be viable in the marketplace.

\section{Key Research Results}

\section{Achievement}

NREL leveraged funding from key stakeholders and partnered with industry to address a critical gap for medium- and heavy-duty natural gas vehicles.

\section{Key Result}

The first natural gas-powered 11.9-liter engines began commercial production in April of this year. Additional engine performance ratings, up to 400 horsepower, are entering commercial production.

\section{Potential Impact}

A surge in domestic discoveries, paired with affordable prices, could make natural gas a competitive option for commercial and fleet vehicles.
NREL is a national laboratory of the U.S. Department of Energy, Office of Energy Efficiency and Renewable Energy, operated by the Alliance for Sustainable Energy, LLC.

15013 Denver West Parkway Golden, CO 80401 303-275-3000 | www.nrel.gov 